\title{
COMUNICAÇÃO
}

\section{RESISTÊNCIA PARCIAL À NECROSE DOS FRUTOS EM GENÓTIPOS DE CAFÉ ARÁBICA ${ }^{1}$}

\author{
Partial resistance to fruit necrosis in arabic coffee genotypes
}

\author{
Gustavo Hiroshi Sera², Tumoru Sera ${ }^{3}$, Dhalton Shiguer Ito $^{4}$, Leandro del Grossi ${ }^{5}$, \\ Fabio Seidi Kanayama ${ }^{6}$, Clayton Ribeiro Alegre ${ }^{7}$
}

\begin{abstract}
RESUMO
Neste trabalho, objetivou-se identificar em genótipos de café arábica (Coffea arabica L.) fontes de resistência à necrose de frutos em condições de campo. As variáveis resistência à necrose de frutos ("NF"), quantidade média de frutos por nó produtivo ("FN") e índice de luminosidade dentro da copa da planta ("LUM") foram avaliadas em ensaio de campo no IAPAR (Londrina), em dezembro de 2004, em cafeeiros com três anos de idade. Foi avaliada a variável "NF", atribuindo notas de 1 a 5 sendo 1 para plantas com $0 \%$ a $5 \%$ de frutos necrosados. "FN" foi avaliada seguindo uma escala de notas de 1 a 5 , onde 1 representa plantas com 0 a 3 frutos/ nó e nota 5 com mais do que 15 frutos/ nó. A avaliação da variável "LUM" foi visual e seguiu as notas de 1 a 5 , onde 1 representa plantas com pouca luminosidade dentro da copa da planta. Dos 19 genótipos avaliados, 2 apresentaram moderada resistência, 7 moderada suscetibilidade, 5 suscetíveis e 5 altamente suscetíveis. As cultivares Obatã IAC 1669-20 e Catucaí Vermelho 4-79 apresentaram o melhor nível de resistência parcial de campo, ou seja, com moderada resistência à necrose de frutos associada ao Colletotrichum spp.
\end{abstract}

Termos para indexação: Antracnose, Coffea arabica, Colletotrichum spp., melhoramento genético.

\section{ABSTRACT}

The aim of this research was to identify in Coffea arabica L. coffee genotypes resistance sources to fruit necrosis in field conditions. The variables fruit necrosis ("NF"), fruits per productive nodes average ("FN") and luminosity index inside of the plant canopy ("LUM") were evaluated in field assay at IAPAR (Londrina), in December 2004 on three years old coffee trees. The "NF" variable were evaluated attributing scores from 1 to 5 , where score 1 represented plants with 0 to $5 \%$ of necrosed fruits. "FN" were evaluated following a score scale from 1 to 5 , where score 1 represented plants with 0 to 3 fruits/ node and score 5 with more than 15 fruits/ node. The evaluation of the variable "LUM" was visual and followed the scores from 1 to 5, where score 1 represented plants with low luminosity inside the canopy. Out of the 19 evaluated coffee genotypes, 2 presented moderate resistance, 7 moderate susceptibility, 5 susceptibility and 5 high susceptibility. The cultivars Obatã IAC 1669-20 and Catucaí Vermelho 4-79 presented the best level of partial field resistance, or either, with moderate resistance to fruit necrosis associated to Colletotrichum spp.

Index terms: Antracnosis, Coffea arabica, coffee breeding, Colletotrichum spp.

\section{(Recebido em 23 de agosto de 2007 e aprovado em 28 de maio de 2008)}

Várias espécies do fungo do gênero Colletotrichum são agentes etiológicos de diferentes doenças na cultura do café. A mais conhecida é o C. kahawae, causador da doença "Coffee Berry Disease" (CBD), a qual normalmente ocorre em regiões de altitudes elevadas da África. Recentemente no Brasil, espécies do gênero Colletotrichum, principalmente C. gloeosporioides, vêm sendo associadas aos sintomas de necrose e

\footnotetext{
${ }^{1}$ Parte da dissertação de Mestrado do primeiro autor, apresentada ao Departamento de Biologia Geral da UEL.

'Engenheiro Agrônomo, Doutor - Área de Melhoramento e Genética Vegetal/AMG - Instituto Agronômico do Paraná/IAPAR - Rodovia Celso Garcia Cid, Km 375 - Três Marcos - Cx. P. 481 - 86001-970 - Londrina, PR - gustavosera@uol.com.br

${ }^{3}$ Engenheiro Agrônomo, Doutor, Pesquisador - Área de Melhoramento e Genética Vegetal/AMG - Instituto Agronômico do Paraná/IAPAR - Rodovia Celso Garcia Cid, Km 375 - Três Marcos - Cx. P. 481 - 86001-970 - Londrina, PR - tsera@uol.com.br

${ }^{4}$ Biólogo, Doutorando - Área de Melhoramento e Genética Vegetal/AMG - Conselho Nacional de Desenvolvimento Científico e Tecnológico/ CNPq - Instituto Agronômico do Paraná/IAPAR - Rodovia Celso Garcia Cid, Km 375 - Três Marcos - Cx. P. 481 - $86001-970$ - Londrina, PR itods@uol.com.br

${ }^{5}$ Engenheiro Agrônomo - Área de Melhoramento e Genética Vegetal/AMG - Secretaria de Estado da Ciência, Tecnologia e Ensino Superior/SETI Instituto Agronômico do Paraná/IAPAR - Rodovia Celso Garcia Cid, Km 375 - Três Marcos - Cx. P. 481 - 86001-970 - Londrina, PR leandrodelgrossi@ig.com.br

${ }^{6}$ Biólogo, Meste - Área de Melhoramento e Genética Vegetal/AMG - Empresa Brasileira de Pesquisa Agropecuária/EMBRAPA - Instituto Agronômico do Paraná/IAPAR - Rodovia Celso Garcia Cid, Km 375 - Três Marcos - Cx. P. 481 - 86001-970 - Londrina, PR - fseidi@uol.com.br

${ }^{7}$ Técnico Agrícola - Área de Melhoramento e Genética Vegetal/AMG - Empresa Brasileira de Pesquisa Agropecuária/EMBRAPA - Instituto Agronômico do Paraná/IAPAR - Rodovia Celso Garcia Cid, Km 375 - Três Marcos - Cx. P. 481 - 86001-970 - Londrina, PR - ribeiroclayton@gmail.com
} 
escurecimento de flores, frutos, ramos e folhas de cafeeiros (DORIZZOTTO, 1993; FERREIRA et al., 2005; JULIATTI et al., 2000; OROZCO-MIRANDA, 2003; PARADELAFILHO et al., 2001; SILVA et al., 2005).

Os principais sintomas associados à presença de Colletotrichum spp. são: escurecimento e morte das estípulas dos nós; manchas irregulares necróticas próximas às margens das folhas e queda; desenvolvimento de manchas pardas no caule verde podendo levar a plântula à morte; lesões necróticas de pardas a negras em gemas, flores, chumbinhos e frutos, provocando a morte e a queda destes e, enegrecimento e morte de ramos (PARADELAFILHO et al., 2001), sendo a morte das estruturas reprodutivas e dos ramos os mais prejudiciais para o cafeeiro. Sintomas similares de necrose de frutos e seca de ramos estão sendo atribuídos à infecção de diferentes espécies de Phoma (SALGADO \& PFENNING, 2000).

Atualmente, existe pouca pesquisa sobre o controle dos sintomas de necrose de flores, frutos, folhas e ramos associados aos fungos Colletotrichum spp., Phoma spp. e Ascochyta. Assim, é de grande importância a obtenção de cultivares com resistência parcial ou total à necrose de flores, frutos, folhas e ramos. Muitos pesquisadores relatam sobre a resistência do café ao $C$. kahawae, que ocorre na África, em diversos genótipos (VOSSEN \& WALYARO, 1980). Entretanto, pouco se conhece sobre a resistência de cafeeiros aos sintomas descritos por Paradela-Filho et al. (2001) associados ao Colletotrichum spp. e também ao C. gloeosporioides. Orozco-Miranda (2003) realizou testes de resistência ao $C$. gloeosporioides em hipocótilos e frutos verdes e maduros destacados e encontrou diferentes níveis de resistência nas cultivares de café estudadas. Sera et al. (2007) encontraram diferentes níveis de resistência parcial à necrose de frutos associada à presença de Colletotrichum spp. em avaliações de campo em cultivares e seleções de Coffea arabica L..

Em ensaio de campo instalado para avaliar a resistência à ferrugem em cultivares de café arábica, na Estação Experimental do IAPAR, foi observada incidência homogênea, alta e severa de necrose de frutos. Neste trabalho, objetivou-se realizar avaliação preliminar em genótipos de café arábica para a resistência à necrose dos frutos associada ao Colletotrichum spp., com os mesmos sintomas descritos por Paradela-Filho et al. (2001).

O ensaio de campo foi instalado em 20 de agosto de 2002 na Estação Experimental do Instituto Agronômico do Paraná (IAPAR) em Londrina, PR, Brasil, no espaçamento $2,5 \mathrm{~m}$ x 0,5 m. A altitude local é de $585 \mathrm{~m}$, com média anual histórica da temperatura, precipitação e umidade relativa do ar, respectivamente, de $20,8^{\circ} \mathrm{C}, 1610 \mathrm{~mm}$ e $71 \%$.
No IAPAR (Londrina-PR), em todas as amostras de folhas, ramos e frutos escurecidos e necrosados de cafeeiros (Coffea arabica L.), com os mesmos sintomas descritos por Paradela-Filho et al. (2001), foi verificada a presença de Colletotrichum spp., enquanto Silva et al. (2005) identificaram os isolados como sendo $C$. gloeosporioides.

As variáveis necrose dos frutos (NF), quantidade média de frutos por nó produtivo $(\mathrm{FN})$ e índice de luminosidade dentro da copa da planta (LUM) foram avaliadas visualmente em dezembro de 2004, e em cafeeiros com três anos de idade, os quais apresentavam alta quantidade de frutos. Em todos os genótipos, as avaliações foram realizadas em frutos, predominantemente, nos estádios de chumbinho e expansão dos frutos.

Foram avaliadas 20 plantas de cada um dos genótipos: IAPAR-59 III-1-9, IAPAR-59 III-1-10, IAPAR59 (originado de várias plantas), Tupi IAC 1669-33 (IAPAR 88480-8), Tupi IAC 1669-33, Obatã IAC 1669-20, Costa Rica 95 T-8667, Catuaí Vermelho IAC-99, Catuaí “Arrepiado”, Ouro Verde IAC H5010-5, Rubi MG-1192, Mundo Novo IAC 464-12, Icatu Precoce IAC-3282, Catucaí 785-15, Catucaí Vermelho 4-79, Catucaí-Açú, Palma II, Rume Sudan IAC-1139, Villa Sarchi (Icafé - Costa Rica).

A resistência à necrose dos frutos foi avaliada visualmente em todos os ramos e nós produtivos da planta com frutos nos estádios de chumbinho e expansão, atribuindo notas de 1 a 5 , com as respectivas porcentagens de frutos jovens necrosados, onde: $1=0 \%$ a $5 \% ; 2=6 \%$ a $10 \% ; 3=11 \%$ a $20 \% ; 4=21 \%$ a $40 \%$; e $5=$ mais do que $41 \%$. As reações de resistência das cultivares foram presumidas a partir da nota média de ocorrência de necrose dos frutos. As reações de resistência foram: moderada resistência (nota média de 1,10 a 1,99), moderada suscetibilidade (nota média de 2,00 a 2,99), suscetível (nota média de 3,00 a 3,99) e altamente suscetível (nota média de $4,00$ a 5,00$)$

Foi avaliada a quantidade média de frutos por nó produtivo da planta ("FN") dos melhores ramos produtivos seguindo uma escala modificada de notas de 1 a 5 usada por Sera et al. (2007), onde: $1=0$ a 3 frutos/ nó; $2=4$ a 7 frutos/ nó; 3 = 8 a 11 frutos/ nó; 4 = 12 a 15 frutos/ nó; e 5 = mais do que 15 frutos/ nó. Somente as plantas com notas de FN maior ou igual a 3 foram consideradas nas avaliações da necrose de frutos. Entretanto, algumas plantas suscetíveis e altamente suscetíveis apresentavam alta quantidade de necrose mesmo com notas de FN 1 e 2 . Assim, cafeeiros com notas de FN 1 e 2 e com notas da variável necrose de frutos (NF) igual a 3, 4 e 5 foram consideradas nas avaliações. 
A avaliação do índice de luminosidade dentro da copa da planta ("LUM") foi visual e seguiu uma escala de notas de 1 a 5 , onde: nota 1 = plantas muito fechadas e com pouca luminosidade dentro da copa da planta, onde não é possível observar os frutos que estão dentro da copa; nota 2 = visibilidade de 1 a $25 \%$ dos frutos; nota $3=$ visibilidade de 26 a $50 \%$ dos frutos; nota $4=$ visibilidade de 51 a $75 \%$ dos frutos; nota $5=$ plantas com alta incidência de luz dentro da copa, onde é possível observar entre 76 a $100 \%$ dos frutos.

$\mathrm{O}$ coeficiente de variação fenotípico $\left(\mathrm{CV}_{\mathrm{F}}\right)$ de cada genótipo foi estimado para verificar quais tratamentos estavam segregantes para a variável necrose de frutos. $\mathrm{O}$ menor $\mathrm{CV}_{\mathrm{F}}$ observado no ensaio foi o da cultivar Icatu Precoce IAC-3282. Portanto, o $\mathrm{CV}_{\mathrm{F}}$ desta cultivar foi usada como coeficiente de variação ambiental $\left(\mathrm{CV}_{\mathrm{E}}\right)$ para estimar o coeficiente de determinação genotípico dentro dos genótipos (b) através da fórmula: $\mathrm{CV}_{\mathrm{G}} / \mathrm{CV}_{\mathrm{F}} \times 100$, sendo $\mathrm{CV}_{\mathrm{G}}=\mathrm{CV}_{\mathrm{F}}-\mathrm{CV}_{\mathrm{E}}$.

Neste ensaio de campo, foram observados genótipos com reações de resistência à necrose dos frutos desde moderadamente resistentes até altamente suscetível. Dos 19 genótipos avaliados, 2 apresentaram moderada resistência, 8 moderada suscetibilidade, 4 suscetíveis e 5 altamente suscetíveis (Tabela 1).

A cultivar Obatã IAC 1669-20 e a seleção Catucaí Vermelho 4-79 foram as que apresentaram melhor nível de resistência parcial com pouca perda na produção. Enquanto nesses genótipos a perda na produção foi em torno de $5 \%$ a $10 \%$, em cultivares como a Costa Rica 95 e Palma II a perda foi mais que $50 \%$. Em cafeeiros com moderada resistência, os danos na produção podem não ser significativas, pois os nutrientes que iriam para os $10 \%$ de frutos que necrosaram suprem o restante dos frutos.

Os tratamentos 'IAPAR-59' III-1-9 e 'IAPAR-59' (originado de várias plantas) apresentaram moderada suscetibilidade à necrose dos frutos, do mesmo modo que Sera et al. (2007) observaram. Entretanto, o tratamento 'IAPAR-59 III-1-10' foi altamente suscetível à doença. Os tratamentos 'Tupi IAC 1669-33' (IAPAR 88480-8) e 'Tupi IAC 1669-33' apresentaram moderada suscetibilidade. Sera et al. (2007) classificaram a 'Tupi IAC 1669-33' como suscetível. Então, tanto nas cultivares IAPAR-59 quanto na Tupi IAC 1669-33 está ocorrendo segregação para a resistência à necrose dos frutos, necessitando selecionar entre as progênies dessas cultivares.

A ‘Catuaí Vermelho IAC-99' ('Caturra' x 'Mundo Novo') apresentou moderada suscetibilidade, enquanto que o ‘Catuaí Arrepiado' foi suscetível à doença, indicando que também existe segregação entre os genótipos do germoplasma Catuaí. Além disso, a cultivar Rubi MG-1192 ('Catuaí' x 'Mundo Novo') apresentou suscetibilidade, confirmando os resultados de Sera et al. (2007). A cultivar Ouro Verde IAC H5010-5 ('Catuaí' x 'Mundo Novo') mostrou moderada suscetibilidade e a 'Mundo Novo IAC 464-12' suscetibilidade. Neste ensaio, os genótipos 'Catuaí Arrepiado' e 'Mundo Novo IAC 464-12' foram classificadas como suscetíveis (Tabela 1). Entretanto, podem ser consideradas altamente suscetíveis, pois apresentaram alta porcentagem de frutos necrosados mesmo com alta nota média do índice de luminosidade no interior da copa da planta e com poucos frutos por nó produtivo, ou seja, com condições desfavoráveis para a necrose de frutos segundo Sera et al. (2007). Períodos contínuos com umidade elevada favorecem o desenvolvimento de Colletotrichum spp. e, quanto maior o período de molhamento dos tecidos das plantas, maior é a colonização deste fungo (PARADELAFILHO et al., 2001). Por esses dois motivos, a alta luminosidade dentro da copa, com conseqüentes diminuições da umidade relativa do ar e período de molhamento, pode ser desfavorável para a necrose dos frutos. 'Icatu IAC-3282' foi classificada como suscetível. Entretanto, esta poderia se comportar como altamente suscetível se estivesse com alta quantidade de frutos por nó e menos incidência de luminosidade dentro da copa da planta. Os cafeeiros 'Rubi MG-1192', 'Rume Sudan IAC1139' e 'Villa Sarchi' também poderiam ser mais suscetíveis se apresentassem mais frequiência de plantas com notas de FN 4 e 5.

A 'Catuaí Vermelho IAC-99' foi considerada como moderadamente suscetível mesmo apresentando nota média de necrose de frutos $(\mathrm{NF}=2,00)$ próxima dos genótipos moderadamente resistentes Obatã IAC 1669-20 $(\mathrm{NF}=1,82)$ e Catucaí Vermelho 4-79 ( $\mathrm{NF}=1,90)$, pois a quantidade de frutos por nó produtivo na 'Catuaí' foi baixa, com 30,3\% das plantas com notas de FN maior ou igual a 3. Em contrapartida, em outros genótipos moderadamente suscetíveis como o 'IAPAR-59 III-1-9', 'Tupi IAC 1669-33' (IAPAR 88480-8), 'IAPAR-59' (originado de várias plantas), 'Catucaí-Açú', 'Ouro Verde IAC H5010-5' e 'Tupi IAC 166933' foram observadas, respectivamente, 89,5\%, 77,3\%, $96,9 \%, 81,9 \%, 95,2 \%$ e $100 \%$ de plantas com notas de FN maior ou igual a 3 (Tabela 2). Sera et al. (2007) também classificaram a 'Catuaí Vermelho IAC-99' como moderadamente suscetível, a qual estava com baixa quantidade de frutos por nó e alto índice de luminosidade dentro da copa da planta em comparação com outros genótipos. 
Tabela 1 - Notas médias da incidência de necrose de frutos (NF), quantidade média de frutos por nó produtivo (FN) e índice de luminosidade dentro da copa da planta (LUM), e reações de resistência de cafeeiros arábicos à necrose de frutos, em condições de campo, avaliadas em dezembro de 2004 no IAPAR (Londrina, PR, Brasil).

\begin{tabular}{lcccc}
\hline \multicolumn{1}{c}{ Genótipos } & $\mathrm{NF}^{(1)}$ & $\mathrm{FN}^{(2)}$ & LUM $^{(3)}$ & Resistência $^{(4)}$ \\
\hline Palma II & 4,35 & 3,53 & 5,00 & $\mathrm{AS}$ \\
Costa Rica 95 T-8667 (Icafé - Costa Rica) & 4,00 & 4,75 & 4,19 & $\mathrm{AS}$ \\
IAPAR-59 III-1-10 & 4,00 & 4,00 & 3,45 & $\mathrm{AS}$ \\
Mundo Novo IAC 464-12 & 3,83 & 2,67 & 4,33 & $\mathrm{~S}$ \\
Icatu Precoce IAC-3282 & 3,75 & 2,25 & 5,00 & $\mathrm{~S}$ \\
Catuaí Arrepiado & 3,67 & 2,22 & 4,22 & $\mathrm{~S}$ \\
Catucaí 785-15 & 3,60 & 3,95 & 3,75 & $\mathrm{~S}$ \\
Rubi MG-1192 & 3,50 & 3,50 & 3,00 & $\mathrm{~S}$ \\
Rume Sudan IAC-1139 & 3,13 & 3,38 & 4,75 & $\mathrm{~S}$ \\
Tupi IAC 1669-33 & 2,80 & 3,65 & 3,85 & $\mathrm{MS}$ \\
Ouro Verde IAC H5010-5 & 2,65 & 3,45 & 3,95 & $\mathrm{MS}$ \\
Catucaí-Açú & 2,61 & 4,28 & 3,33 & $\mathrm{MS}$ \\
IAPAR-59 (originado de várias plantas) & 2,61 & 4,55 & 3,64 & $\mathrm{MS}$ \\
Villa Sarchi (Icafé - Costa Rica) & 2,50 & 3,20 & 3,50 & $\mathrm{MS}$ \\
Tupi IAC 1669-33 (IAPAR 88480-8) & 2,39 & 3,89 & 3,83 & MS \\
IAPAR-59 III-1-9 & 2,29 & 4,12 & 3,35 & MS \\
Catuaí Vermelho IAC-99 & 2,00 & 3,43 & 3,29 & MS \\
Catucaí Vermelho 4-79 & 1,90 & 3,42 & 3,08 & MR \\
Obatã IAC 1669-20 & 1,82 & 3,76 & 3,18 & MR \\
\hline
\end{tabular}

${ }^{(1)}$ nota $1=0 \%$ a $5 \%$ de frutos necrosados; nota $5=$ mais que $41 \%$ de frutos necrosados. ${ }^{(2)}$ nota $1=0$ a 3 frutos/ nó; nota $5=$ mais que 15 frutos/ nó. ${ }^{(3)}$ nota $1=$ plantas com pouca luminosidade dentro da copa da planta; nota $5=$ plantas com alta incidência de luz, onde é possível observar entre 76 a $100 \%$ dos frutos. ${ }^{\left({ }^{4}\right)} \mathrm{AS}=$ altamente suscetível; $\mathrm{S}=$ suscetível; MS = moderadamente suscetível; $\mathrm{MR}=$ moderadamente resistente.

Tabela 2 - Freqüência das notas da variável quantidade de frutos por nó produtivo (FN) dos genótipos de Coffea arabica avaliados em dezembro de 2004 (IAPAR, Londrina, PR).

\begin{tabular}{lccccc}
\hline \multicolumn{1}{c}{ Genótipos } & \multicolumn{5}{c}{ Freqüência de notas FN (\%) ${ }^{(1)}$} \\
\cline { 2 - 6 } & 1 & 2 & 3 & 4 & 5 \\
\hline Palma II & --- & 28,6 & 28,6 & 33,3 & 9,5 \\
Costa Rica 95 T-8667 & --- & 5,9 & --- & 23,5 & 70,6 \\
IAPAR-59 III-1-10 & --- & 8,3 & 16,7 & 58,3 & 16,7 \\
* Mundo Novo IAC 464-12 & 31,3 & 37,4 & 31,3 & --- & -- \\
* Icatu Precoce IAC-3282 & 30,0 & 65,0 & 5,0 & --- & --- \\
* Catuaí Arrepiado & 60,0 & 20,0 & 20,0 & --- & 28,6 \\
Catucaí 785-15 & --- & 9,5 & 23,8 & 38,1 & --- \\
* Rubi MG-1192 & 90,0 & --- & 5,0 & 5,0 & --- \\
* Rume Sudan IAC-1139 & 50,0 & 5,6 & 27,8 & 16,7 & 9,5 \\
Tupi IAC 1669-33 & --- & --- & 47,6 & 42,9 & 4,8 \\
Ouro Verde IAC H5010-5 & --- & 4,8 & 57,1 & 33,3 & 36,5 \\
Catucaí-Açú & 13,6 & 4,5 & 13,6 & 31,8 & 62,5 \\
IAPAR-59 (originado de várias plantas) & --- & 3,1 & 9,4 & 25,0 & --- \\
* Villa Sarchi (Icafé - Costa Rica) & 20,0 & 30,0 & 45,0 & 5,0 \\
Tupi IAC 1669-33 (IAPAR 88480-8) & 22,7 & --- & 18,2 & 31,8 & 27,3 \\
IAPAR-59 III-1-9 & --- & 10,5 & 26,3 & 26,3 & 36,9 \\
* Catuaí Vermelho IAC-99 & 45,5 & 24,2 & 18,2 & 9,1 & 3,0 \\
Catucaí Vermelho 4-79 & 5,3 & 31,6 & 42,0 & 15,8 & 5,3 \\
Obatã IAC 1669-20 & 9,1 & 13,6 & 31,8 & 31,8 & 13,6 \\
\hline
\end{tabular}

* Cultivares com freqüência de plantas com notas de FN 1 e 2 e" $50 \%$.

${ }^{(1)}$ Três traços (-) indicam ausência de plantas com a respectiva nota de FN. 
Neste trabalho, foi avaliada a necrose de frutos e não a necrose de flores. É possível que os cafeeiros com alta frequiência de plantas com notas de FN 1 e 2, podem ter apresentado menor quantidade de frutos por nó, pois pode ter ocorrido a necrose das flores. Portanto, é provável que alguns genótipos sejam mais suscetíveis à necrose de flores como em 'Mundo Novo IAC 464-12', 'Icatu IAC3282', 'Catuaí Arrepiado', 'Rubi MG-1192', 'Rume Sudan IAC-1139', 'Villa Sarchi' e 'Catuaí Vermelho IAC-99', as quais apresentaram alta freqüência de plantas com notas de FN 1 e 2.

Apesar do 'Catucaí Vermelho 4-79' apresentar moderada resistência, as cultivares Catucaí-Açú e Catucaí 785-15 foram, respectivamente, moderadamente suscetível e suscetível, indicando a ocorrência de segregação para a suscetibilidade entre genótipos do germoplasma Catucaí do mesmo modo que Sera et al. (2007) demonstraram. Para tanto, nos diversos cafeeiros como as derivadas do 'Icatu', 'Catuaí', 'Catucaí', 'Sarchimor' e outros é necessária a seleção entre e dentro dessas visando a obter genótipos com melhores níveis de resistência parcial, pois, provavelmente, está ocorrendo segregação para a resistência à necrose de frutos dentro desses genótipos.

Na Tabela 3, é apresentada a freqüência, em porcentagem, das diferentes notas da variável NF, coeficiente de variação fenotípica ("CV $\mathrm{F}_{\mathrm{F}}$ ") e coeficiente de determinação genotípica ("b") dentro dos genótipos avaliados. Pela distribuição das freqüências de notas da variável NF e baixos valores de "CV," e "b" observados nos genótipos Palma II, Costa Rica 95, IAPAR-59 III-1-10, Mundo Novo IAC 464-12, Icatu Precoce, Catuaí Arrepiado, Rubi MG-1192, Catuaí Vermelho IAC-99, Catucaí Vermelho 4-79 e Obatã IAC 1669-20 é possível indicar que não está ocorrendo segregação para a resistência ou suscetibilidade à necrose de frutos e que não existe variabilidade genética para a seleção dentro desses cafeeiros. Assim, a seleção 'Catucaí Vermelho 4-79' e a cultivar Obatã IAC 1669-20 além de serem moderadamente resistentes, não estão segregando para a resistência. Os outros tratamentos apresentaram altos valores de " $\mathrm{CV}_{\mathrm{F}}$ " $\mathrm{e}$ " $\mathrm{b}$ " indicando que são segregantes e que é possível melhorar os níveis de resistência pela seleção dentro desses genótipos, com destaque para as cultivares Tupi IAC-1669-33 (IAPAR 88480-8), IAPAR-59 III-1-9 e Catucaí-Açú, as quais apresentaram os maiores valores de " $\mathrm{CV}_{\mathrm{F}}$ " e " $\mathrm{b}$ ", e mais números de classes de notas de necrose dos frutos. É provável que se realizado a seleção dentro das cultivares Tupi IAC-1669-33 e IAPAR-59, essas apresentarão o mesmo nível de resistência da 'Obatã IAC 1669-20', se estiverem com nível nutricional similar, pois ambas possuem o mesmo parental em comum com esta cultivar. Entretanto, é necessário selecionar, de preferência, plantas resistentes com alta quantidade de frutos por nó $(\mathrm{FN}=4 \mathrm{e}$ 5) e com índice de luminosidade não muito alto ( $\mathrm{LUM}=1$, 2 e 3) para evitar erros na seleção de cafeeiros que não sejam resistentes. As plantas resistentes cujas progênies não segregarem para a suscetibilidade deverão ser selecionadas.

É possível observar que a maioria dos cafeeiros apresenta mais necrose de frutos quando as notas de FN foram maior ou igual a 3, como no caso dos genótipos Palma II, IAPAR-59 III-1-10, Mundo Novo IAC 464-12, Icatu Precoce IAC-3282, Catuaí Arrepiado, Catucaí 785-15, Rubi MG-1192, Rume Sudan IAC-1139, Ouro Verde IAC H50105, Catucaí-Açú e Villa Sarchi (Tabela 4). Assim, confirmando a importância da avaliação da variável FN e da eliminação de plantas com notas de FN 1 e 2 para evitar erros na identificação de fontes de resistência. Entretanto, algumas plantas suscetíveis e altamente suscetíveis apresentam alta quantidade de frutos necrosados mesmo com notas de "FN" 1 e 2, como pode ser observado nos genótipos Palma II, Costa Rica 95, Mundo Novo IAC 464-12, Icatu Precoce IAC-3282, Catuaí Arrepiado, IAPAR-59 (originado de várias plantas) e Tupi IAC 1669-33 (IAPAR 88480-8) (Tabela 4). Por este motivo, cafeeiros com notas de FN 1 e 2, porém suscetíveis, foram considerados nas avaliações. A não avaliação das variáveis FN e LUM pode resultar em menor eficiência de seleção.

Em testes de resistência em laboratório com frutos verdes destacados, Orozco-Miranda (2003) encontrou resultados similares ao deste trabalho, pois encontrou resistência nas cultivares Catucaí Vermelho e Tupi e mais suscetibilidade nas cultivares Mundo Novo IAC 319-19 e Rubi MG-1192. Entretanto, muitos resultados foram divergentes quanto às reações de resistência. Essas diferenças quanto à resistência à necrose de frutos associada ao Colletotrichum spp. nas avaliações do presente trabalho, em relação aos testes em hipocótilos e em frutos destacados realizados por Orozco-Miranda (2003) pode ser em razão de: a) existir diferenças entre os diferentes testes de resistência; b) diferenças entre a resistência de frutos e em hipocótilos; c) segregação para a resistência ao Colletotrichum spp. em genótipos do 'Icatu', 'Catucaí', 'Catuaí', 'Sarchimor' e em outros; d) efeito de genes menores modificadores como o vigor vegetativo e arquitetura da planta em condições de campo; e) existe a possibilidade de que o(s) patógeno(s) ou patótipo(s) envolvido(s) na necrose de frutos em Londrina podem ser diferentes em relação ao do Estado de Minas Gerais. 
Tabela 3 - Freqüência, em porcentagem, das notas da variável necrose de frutos (NF), coeficiente de variação fenotípica $\left(\mathrm{CV}_{\mathrm{F}}\right)$ e coeficiente de determinação genotípica (b) dentro dos genótipos de Coffea arabica avaliados em dezembro de 2004 (IAPAR, Londrina, PR).

\begin{tabular}{|c|c|c|c|c|c|c|c|}
\hline \multirow{2}{*}{ Genótipos * } & \multicolumn{5}{|c|}{ Freqüência das notas de NF (\%) } & \multirow{2}{*}{$\mathrm{CV}_{\mathrm{F}} \%$} & \multirow{2}{*}{$\mathrm{b}$} \\
\hline & 1 & 2 & 3 & 4 & 5 & & \\
\hline Palma II & 0 & 0 & 11,7 & 41,2 & 47,1 & 16,12 & 0,173 \\
\hline Costa Rica 95 T-8667 & 0 & 6,2 & 25,0 & 31,3 & 37,5 & 24,15 & 0,448 \\
\hline IAPAR-59 III-1-10 & 0 & 9,0 & 18,2 & 36,4 & 36,4 & 25,00 & 0,467 \\
\hline Mundo Novo IAC 464-12 & 0 & 16,7 & 0 & 66,6 & 16,7 & 25,67 & 0,481 \\
\hline Icatu Precoce IAC-3282 & 0 & 0 & 25,0 & 75,0 & 0 & 13,33 & 0 \\
\hline Catuaí Arrepiado & 0 & 11,1 & 11,1 & 77,8 & 0 & 19,27 & 0,308 \\
\hline Catucaí 785-15 & 5,0 & 5,0 & 30,0 & 45,0 & 15,0 & 27,63 & 0,518 \\
\hline Rubi MG-1192 & 0 & 0 & 50,0 & 50,0 & 0 & 20,20 & 0,340 \\
\hline Rume Sudan IAC-1139 & 0 & 37,5 & 25,0 & 25,0 & 12,5 & 36,03 & 0,630 \\
\hline Tupi IAC 1669-33 & 5,0 & 40,0 & 30,0 & 20,0 & 5,0 & 35,90 & 0,629 \\
\hline Ouro Verde IAC H5010-5 & 5,0 & 40,0 & 40,0 & 15,0 & 0 & 30,67 & 0,565 \\
\hline Catucaí-Açú & 22,2 & 11,1 & 55,6 & 5,6 & 5,6 & 41,83 & 0,681 \\
\hline IAPAR-59 (originado de várias plantas) & 16,1 & 19,4 & 48,4 & 16,1 & 0 & 37,90 & 0,648 \\
\hline Villa Sarchi (Icafé - Costa Rica) & 0 & 60,0 & 30,0 & 10,0 & 0 & 28,28 & 0,529 \\
\hline Tupi IAC 1669-33 (IAPAR 88480-8) & 22,2 & 38,9 & 22,2 & 11,1 & 5,6 & 47,90 & 0,722 \\
\hline IAPAR-59 III-1-9 & 17,6 & 47,1 & 29,4 & 0 & 5,9 & 42,94 & 0,690 \\
\hline Catuaí Vermelho IAC-99 & 10,0 & 90,0 & 0 & 0 & 0 & 15,81 & 0,157 \\
\hline Catucaí Vermelho 4-79 & 8,3 & 91,7 & 0 & 0 & 0 & 15,06 & 0,115 \\
\hline Obatã IAC 1669-20 & 17,6 & 82,4 & 0 & 0 & 0 & 21,55 & 0,381 \\
\hline
\end{tabular}

* Ordem decrescente (do mais suscetível para o mais resistente) com base na nota média da variável NF.

Tabela 4 - Notas médias da necrose de frutos (NF) de plantas com notas 1, 2, 3, 4 e 5 da variável quantidade de frutos por nó produtivo (FN) dos genótipos de Coffea arabica avaliados em dezembro de 2004 (IAPAR, Londrina, PR).

\begin{tabular}{|c|c|c|c|c|c|}
\hline \multirow{2}{*}{ Genótipos ${ }^{(1)}$} & \multicolumn{5}{|c|}{ Notas de FN ${ }^{(2)}$} \\
\hline & 1 & 2 & 3 & 4 & 5 \\
\hline Palma II & --- & 3,17 & 4,50 & 4,29 & 4,50 \\
\hline Costa Rica 95 T-8667 & --- & 4,00 & --- & 3,50 & 4,17 \\
\hline IAPAR-59 III-1-10 & --- & 1,00 & 4,00 & 3,86 & 4,50 \\
\hline Mundo Novo IAC 464-12 & 1,60 & 3,20 & 3,20 & --- & --- \\
\hline Icatu Precoce IAC-3282 & 1,17 & 2,85 & 3,00 & --- & --- \\
\hline Catuaí Arrepiado & 1,50 & 3,25 & 3,50 & --- & --- \\
\hline Catucaí 785-15 & --- & 2,50 & 3,80 & 3,63 & 3,33 \\
\hline Rubi MG-1192 & 1,06 & --- & 4,00 & 3,00 & --- \\
\hline Rume Sudan IAC-1139 & 1,00 & 2,00 & 3,20 & 3,00 & --- \\
\hline Tupi IAC 1669-33 & --- & --- & 2,70 & 2,78 & 2,50 \\
\hline Ouro Verde IAC H5010-5 & --- & 2,00 & 2,58 & 3,00 & 1,00 \\
\hline Catucaí-Açú & 1,00 & 2,00 & 2,67 & 3,14 & 2,13 \\
\hline IAPAR-59 (originado de várias plantas) & --- & 4,00 & 2,33 & 3,00 & 2,50 \\
\hline Villa Sarchi (Icafé - Costa Rica) & 1,25 & 1,67 & 2,33 & --- & 4,00 \\
\hline Tupi IAC 1669-33 (IAPAR 88480-8) & 2,80 & --- & 2,25 & 2,71 & 1,33 \\
\hline IAPAR-59 III-1-9 & --- & 1,50 & 2,20 & 2,20 & 2,43 \\
\hline Catuaí Vermelho IAC-99 & 1,07 & 2,00 & 2,00 & 2,00 & 1,00 \\
\hline Catucaí Vermelho 4-79 & 1,00 & 2,00 & 2,00 & 2,00 & 1,00 \\
\hline Obatã IAC 1669-20 & 1,00 & 1,67 & 2,00 & 2,00 & 1,00 \\
\hline
\end{tabular}

(1) Cultivares ordenadas decrescentemente com base na nota média de incidência de necrose de frutos.

(2) Três traços (-) indicam ausência de plantas com a respectiva nota de quantidade de frutos por nó produtivo. 
Neste trabalho, nenhuma das plantas avaliadas com "FN" maior ou igual a 3 (boa frutificação) apresentou ausência de sintomas ou resistência completa à necrose de frutos, indicando que a resistência do(s) gene(s) é parcial. A resistência pode ser derivada de Coffea canephora Pierre ex Froehn, pois tanto a cultivar Obatã IAC 1669-20 (Sarchimor) e a seleção 'Catucaí Vermelho 4-79' apresentam genes desta espécie, do mesmo modo que Sera et al. (2007) concluíram. Vossen \& Walyaro (1980) relataram que, provavelmente, a resistência do "Híbrido de Timor" ao $C$. kahawae é proveniente de Coffea canephora. Assim, similarmente, é possível ocorrer no caso da necrose de frutos deste trabalho. Orozco-Miranda (2003) também encontrou em genótipos do Sarchimor e Catucaí como os mais resistentes ao C. gloeosporioides, ambos com genes de Coffea canephora.

\section{REFERÊNCIAS BIBLIOGRÁFICAS}

DORIZZOTTO, A. Caracterização morfológica e patogenicidade de Colletotrichum sp. associados a cafeeiros (Coffea arabica L.) em dois municípios de Minas Gerais. 1993. 67 f. Dissertação (Mestrado) Escola Superior de Agricultura de Lavras, Lavras, 1993.

FERREIRA, J. B.; ABREU, M. S. de; PEREIRA, I. S.; OROZCO-MIRANDA, E. F. Progresso da antracnose em folhas de cafeeiros no campo. In: SIMPÓSIO DE PESQUISA DOS CAFÉS DO BRASIL, 4., 2005, Londrina, PR. Anais... Londrina, 2005. CD-ROM.

\section{JULIATTI, F. C.; SILVA, C. C. N.; GONÇALVES FILHO,}

L. R. Estudos das características fisiológicas e genéticas de isolados de Colletotrichum spp. coletados em lavouras cafeeiras (Coffea arabica) de Minas Gerais: 1 . testes de patogenicidade e análise molecular. In: SIMPÓSIO DE PESQUISA DOS CAFÉS DO BRASIL, 1., 2000, Poços de Caldas, MG. Resumos expandidos..
Brasília, DF: Embrapa Café; Belo Horizonte: Minasplan, 2000. v. 1, p. 215-218.

OROZCO-MIRANDA, E. F. Caracterização morfológica, molecular, bioquímica e patogênica de isolados de Colletotrichum spp. associados ao cafeeiro em Minas Gerais e comparação com Colletotrichum kahawae. 2003. 147 f. Tese (Doutorado em Agronomia) Universidade Federal de Lavras, Lavras, 2003.

PARADELA-FILHO, O.; PARADELA, A. L.; THOMAZIELLO, R. A.; RIBEIRO, I. J. A.; SUGIMORI, M. H.; FAZUOLI, L. C. O complexo Colletotrichum do cafeeiro. Boletim Técnico IAC, Campinas, n. 191, 2001.

SALGADO, M.; PFENNING, L. H. Identificação e caracterização morfológica de espécies de Phoma do cafeeiro no Brasil. In: SIMPÓSIO DE PESQUISA DOS CAFÉS DO BRASIL, 1., 2000, Poços de Caldas. Resumos expandidos... Brasília, DF: Embrapa Café; Belo Horizonte: Minasplan, 2000. p. 183-186.

SERA, G. H.; SERA, T.; ITO, D. S.; AZEVEDO, J. A. de; RIBEIRO-FILHO, C.; MATA, J. S. da. Partial resistance to fruit necrosis associated to Colletotrichum spp. among arabic coffee genotypes. Brazilian Archives of Biology and Technology, v. 50, n. 3, p. 395-402, 2007.

SILVA, M. R. L.; MENEGUIM, L.; GONÇALVES, J. S.; PISTORI, J. F.; LEITE JUNIOR, R. P. Caracterização de Colletotrichum spp. associado ao cafeeiro no Estado do Paraná. In: SIMPÓSIO DE PESQUISA DOS CAFÉS DO BRASIL, 4., 2005, Londrina, PR. Anais... Brasília, DF: Embrapa Café, 2005. CD-ROM.

VOSSEN, H. A. M. van der; WALYARO, D. J. A. Breeding for resistance to coffee berry disease in Coffea arabica L. Brazilian Archives of Biology and Technology, v. 29, p. 777-791, 1980. 